\title{
Menaquinone-4 Production by a Mutant of Flavobacterium sp. 238-7
}

\author{
Yoshiki TANI and Naoki SaKURAI \\ Research Center for Cell and Tissue Culture, Faculty of Agriculture, \\ Kyoto University, Kyoto 606, Japan
}

Received March 30, 1987

\begin{abstract}
A considerable amount of menaquinone (MK)-4 was found in cells of a 1-hydroxy-2naphthoate-resistant mutant, strain HNA 250-15, which was derived from Flavobacterium sp. 2387 , in which MK-6 is the major isoprenoid quinone. The MK-4 productivity was further improved by making the mutant resistant to usnic acid and menadione. The amount of MK produced by the resultant mutant, strain $\mathrm{K}_{3}-15$, produced $125.4 \mathrm{mg} / 1$ of culture broth and $12.8 \mathrm{mg} / \mathrm{g}$ of dry cell weight, in the ratio of MK-4 and MK- 6 of $6: 1$, under the optimal culture conditions in the presence of cedar wood oil.
\end{abstract}

Previously, we reported that Flavobacterium meningosepticum, which contains menaquinone $\left(\mathrm{MK}\right.$, vitamin $\left.\mathrm{K}_{2}\right)-6^{1)}$ as the component of isoprenoid quinone, newly acquired the ability to produce $\mathrm{MK}-5^{2)}$ by making it resistant to 1-hydroxy-2-naphthoate (HNA), an analog of the biosynthetic intermediate of MK. It was the first case of a change in the MK pattern in the same microorganism. During further study to develop a new fermentative process for $\mathrm{MK}$ production, an HNA-resistant mutant of Flavobacterium sp. 238-7, which produced MK-6 as the major component of respiratory quinone with some minor components, showed an increase in MK productivity due to the increased production of a minor component of MK. The present paper deals with the identification of the newly formed MK as MK-4, which is provided for clinical use by a chemical process, and the improvement of the MK-4 production by derivation of a mutant and optimization of the cultural conditions to improve the MK-4 production.

\section{MATERIALS AND METHODS}

Chemicals. Usnic acid, menadione (vitamin $\mathrm{K}_{3}$ ), linalool, tiglic acid (2-methylcrotonate) and cedar wood oil were purchased from Wako Pure Chemical Industries,
Ltd., and diphenylamine and $\alpha$-pinene from Nakarai Chemicals, Ltd. All other chemicals were prepared or purchased as described previously. ${ }^{1}$ 3)

Microorganisms. Flavobacterium sp. 238-7, which was first isolated as a potent vitamin B-6 producer ${ }^{4)}$ and showed high MK productivity, ${ }^{3)}$ was used as the parent strain in this study.

Medium and cultivation. The glycerol-Polypepton (Daigo) medium used as the bacterial medium in a preceding study ${ }^{3)}$ was used as the basal medium. The addition of HNA and prenyl alcohols to the medium, cultivation and harvesting of cells werre carried out as described previously. ${ }^{1,3)}$

Derivation of mutants. The $N$-methyl- $N^{\prime}$-nitro- $N$ nitrosoguanidine (NTG) and UV treatments for mutagenization were performed in principle in the same way as for $F$. meningosepticum. ${ }^{1}{ }^{\text {) }}$

Analyses. MK was extracted with methanol from cells and determined by high performance liquid chromatography (HPLC). ${ }^{3)}$ Dry cell weight (DCW) was calculated from the optical density using a calibration curve. Physicochemical analysis of MK homologs was performed with measurement of UV and mass spectra. ${ }^{1)}$

\section{RESULTS}

\section{Production of $M K-4$ by an HNA-resistant mutant}

HNA was found to inhibit the MK biosynthesis of $F$. meningosepticum as a possible ana- 
$\log$ of 1,4-dihydroxy-2-naphthoate (DHNA), a biosynthetic intermediate of MK. ${ }^{3)}$ The MK content of Flavobacterium sp. 238-7 was also reduced by cultivation in the medium containing HNA. In the presence of $10^{-4} \mathrm{M}$ HNA, the MK content decreased to $60 \%$ of that in the case of growth without HNA, but the growth was, however, hardly affected. Then, improvement of the MK productivity of Flavobacterium sp. 238-7 was attempted by deriving HNA-resistant mutants. During the mutation process, one strain, which could grow on a plate supplemented with HNA of $300 \mathrm{mg} / 1$, was found to produce a considerable amount of another MK compound in addition to the major component of the major component of the wild type strain (MK-6). After mono-cell selection several times, a strain, HNA 250-15, which constantly produced the newly increased MK was finally obtained. Figure 1 shows the chromatographic patterns on HPLC of extracts from the wild type and mutant strains. The compound that increased in cells of the mutant strain showed a retention time $\left(t_{R}\right)$ corresponding to that of $\mathrm{MK}-4$.

The newly increased MK in strain HNA 250-15 was isolated according to the method described previously. ${ }^{1)}$ Wet cells (45g as DCW) obtained from 31 of culture broth were subjected to the isolation process and $300 \mathrm{mg}$ of MK homologs was obtained. About $50 \mathrm{mg}$ of the yellow oil obtained was dissolved in a small volume of chloroform and then subjected to reversed-phase thin-layer chromatography. ${ }^{2}$ The fraction showing an $R f$ value of 0.51 was collected and crystallized once from
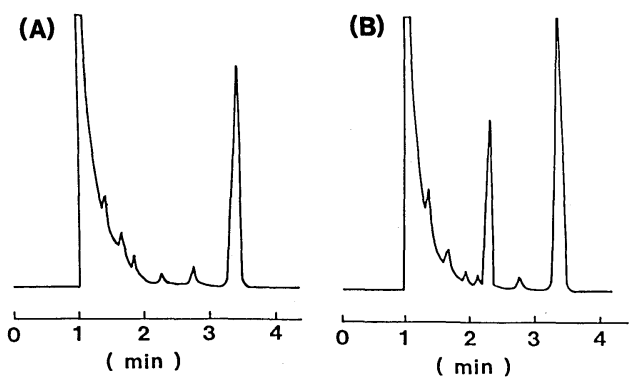

FIG. 1. HPLC of MK from the Wild Type Strain of Flavobacterium sp. 238-7 (A) and Strain HNA 250-15 (B). ethanol. Yellow crystals $(12 \mathrm{mg})$ were obtained.

The melting point of the yellow crystals was 34.0 to $35.5^{\circ} \mathrm{C}$, corresponding to that of $\mathrm{MK}$ 4. ${ }^{5)}$ The UV spectrum of the isolate was typical for MK. The $t_{R}$ on HPLC and the number of isoprenoid units of $\mathrm{MK}$ homologs show a quantitative relationship: a plot of $\ln t_{R}$ versus the number of isoprene units gives a straight line. ${ }^{2)}$ HPLC analysis of the authentic and isolated MK homologs showed that the $t_{R}$ of the isolate corresponded exactly with that of MK-4. The mass spectrum showed a molecular ion peak at $m / z 444$, which corresponds to MK-4, and fragment ion peaks at $m / z 376$ $\left(\mathrm{M}^{+}-68 \times 2\right), m / z 308\left(\mathrm{M}^{+}-68 \times 3\right), m / z 240$ $\left(\mathrm{M}^{+}-68 \times 4\right), m / z 225, m / z \quad 198$ and $m / z 68$. Fragments 376 to 240 were ascribed to compounds formed on the loss of the isoprene units one by one. The 3 intense peaks at $\mathrm{m} / \mathrm{z}$ 225, 198 and 186 are characteristic of MK homologs. From these data, the isolated MK newly increased in strain HNA 250-15 was identified as MK-4.

MK of the wild type strain was also isolated in a similar manner. Physicochemical analyses of the isolated MK homologs indicated that the major component of MK was MK-6, other minor components being MK-3, MK-4 and MK-5, in the order of $t_{R}$ on HPLC.

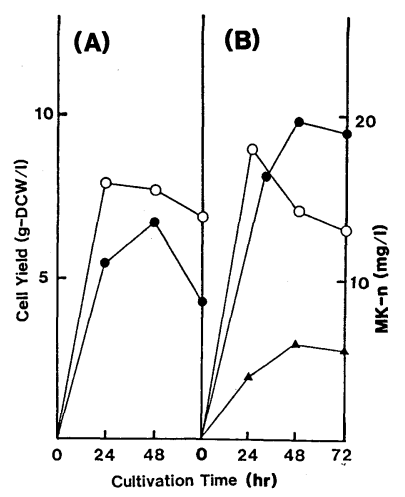

FIG. 2. Production of MK by the Wild Type Strain of Flavobacterium sp. 238-7 (A) and Strain HNA 250-15 (B).

The wild type strain of Flavobacterium 238-7 and strain HNA 250-15 were grown on the basal medium. The amounts of cell yield ( $\bigcirc$ ), MK-4 (A) and MK-6 (O) were determined as described under MATERIALS AND METHODS. 
Figure 2 shows the production of MK- 6 by the wild type strain, and MK-4 and MK- 6 by strain HNA 250-15. The amounts of MK-6 and MK-4 in cells of strain HNA 250-15 increased simultaneously during cultivation, becoming maximum at around $48 \mathrm{hr}$. The maximum yields of MK-6 and MK-4 were $19.7 \mathrm{mg} / \mathrm{l}$ of culture broth and $2.30 \mathrm{mg} / \mathrm{g}$ DCW, and $6.1 \mathrm{mg} / \mathrm{l}$ and $0.71 \mathrm{mg} / \mathrm{g}-\mathrm{DCW}$, respectively.

\section{Improvement of $M K-4$ productivity of strain HNA 250-15}

Flavobacterium sp. 238-7 contains $\mathrm{MK}$ as the sole quinone in the respiratory chain. Among the uncouplers and respiratory inhibitors tested, an uncoupler, usnic acid, strongly inhibited the growth of strain HNA 250-15 at a low concentration. On subsequent mutagenization of the strain, a mutant strain, $\mathrm{USN}^{\mathrm{r}}-2$, which was resistant to $4 \mathrm{mg} / \mathrm{l}$ of usnic acid, was found to produce a much larger amount of MK-4 than strain HNA 250-15, whereas the MK- 6 content was reduced. Strain USN $^{\mathrm{r}}-2$ produced $18.7 \mathrm{mg} / \mathrm{l}$ and $2.26 \mathrm{mg} / \mathrm{g}-$ DCW of MK-4, and $13.1 \mathrm{mg} / 1$ and $1.59 \mathrm{mg} / \mathrm{g}$ -

Table I. EFfects of Carbon Sources on MK Production by Strain $\mathrm{K}_{3}-15$

Cultivation carried out for $48 \mathrm{hr}$ on the basal medium containing each carbon source instead of glycerol.

\begin{tabular}{|c|c|c|c|}
\hline \multirow{2}{*}{$\begin{array}{c}\text { Carbon source } \\
(1 \%, \mathrm{w} / \mathrm{v})\end{array}$} & \multirow{2}{*}{$\begin{array}{l}\text { Cell yield } \\
(\mathrm{g} / \mathrm{l})\end{array}$} & \multicolumn{2}{|c|}{$\begin{array}{c}\text { MK-n produced } \\
(\mathrm{mg} / \mathrm{l})\end{array}$} \\
\hline & & MK-4 & MK-6 \\
\hline Glycerol & 8.19 & 14.7 & 11.0 \\
\hline Glucose & 6.23 & 4.4 & 11.6 \\
\hline Fructose & 5.09 & 2.0 & 6.7 \\
\hline Sorbose & 2.64 & 0.2 & 3.6 \\
\hline Sucrose & 2.80 & 0.5 & 4.8 \\
\hline Soluble starch & 7.64 & 6.1 & 8.5 \\
\hline Ribose & 3.42 & 1.2 & 5.2 \\
\hline Xylose & 3.27 & 0.8 & 5.1 \\
\hline Gluconate $(\mathrm{Na})$ & 3.58 & 1.1 & 5.1 \\
\hline Malate $(\mathrm{Na})$ & 4.05 & 1.5 & 6.3 \\
\hline Succinate $(\mathrm{Na})$ & 3.50 & 1.6 & 5.8 \\
\hline Citrate $(\mathrm{Na})$ & 4.36 & 1.2 & 6.8 \\
\hline Acetate $(\mathrm{Na})$ & 4.20 & 5.9 & 5.7 \\
\hline Fumarate $(\mathrm{Na})$ & 3.90 & 1.7 & 6.0 \\
\hline
\end{tabular}

DCW of MK-6, respectively. The productivity of MK-4 was increased more than three times compared with that of strain HNA 250-15.

Growth of Flavobacterium sp. 238-7 was strictly inhibited by the addition of $10^{-4}$ menadione, an artificial derivative of vitamin $\mathrm{K}$, to the culture medium, and the content of $\mathrm{MK}$ was reduced in the presence of $10^{-5} \mathrm{M}$ menadione. Derivation of menadione-resistant mutants was then carried out for enhancement of the MK productivity using strain $\mathrm{USN}^{\mathrm{r}}-2$ as the parent strain. Among the mutant strains obtained, strain $\mathrm{K}_{3}-15$, which was resistant to $20 \mathrm{mg} / \mathrm{l}$ of menadione showed the highest contents of MK-4 and MK-6. The strain produced $23.6 \mathrm{mg} / \mathrm{l}$ and $3.3 \mathrm{mg} / \mathrm{g}-\mathrm{DCW}$ of MK-4, and $14.2 \mathrm{mg} / 1$ and $2.0 \mathrm{mg} / \mathrm{g}-\mathrm{DCW}$ of MK-6. The total MK productivity was increased about three times compared with that of the wild type strain.

\section{Production of $M K-4$ by strain $K_{3}-15$}

The cultural conditions for MK production was investigated with strain $\mathrm{K}_{3}-15\left(\mathrm{HNA}^{\mathrm{r}}\right.$, usnic $\operatorname{acid}^{\mathrm{r}}$ and menadione ${ }^{\mathrm{r}}$ ).

\section{Table II. EfFects of Nitrogen Sources on MK} Production by Strain $\mathrm{K}_{3}-15$

Cultivation was carried out for $48 \mathrm{hr}$ on the basal medium containing each nitrogen source instead of Polypepton.

\begin{tabular}{lccr}
\hline \multicolumn{1}{c}{\begin{tabular}{c} 
Nitrogen source \\
\multicolumn{1}{c}{$(1.5 \%, \mathrm{w} / \mathrm{v})$}
\end{tabular}} & $\begin{array}{c}\text { Cell yield } \\
(\mathrm{g} / \mathrm{l})\end{array}$ & \multicolumn{2}{c}{$\begin{array}{c}\text { MK-n produced } \\
(\mathrm{mg} / \mathrm{l})\end{array}$} \\
\cline { 3 - 4 } & & MK-4 & MK-6 \\
\hline Polypepton (Daigo) & 7.09 & 16.0 & 12.0 \\
Peptone (Mikuni) & 6.08 & 3.6 & 8.0 \\
Bacto-tryptone & 6.63 & 3.6 & 8.0 \\
Peptone (BBL) & 6.00 & 2.6 & 10.3 \\
Proteose peptone (Difco) & 6.08 & 0.4 & 7.1 \\
Casein (from milk) & 4.20 & 0.4 & 6.0 \\
Casamino acids & 3.42 & 0.6 & 4.2 \\
Casamino acids & 3.73 & 0.8 & 3.8 \\
$\quad$ (vitamin-free) & & & \\
Corn steep liquor & 4.83 & 0.6 & 6.1 \\
Meat extract & 2.64 & 0.1 & 2.5 \\
Malt extract & 1.01 & trace & 0.9 \\
Yeast extract & 5.61 & 1.4 & 8.1 \\
Glutamate (Na) & 5.61 & 1.5 & 5.6 \\
Soybean hydrolyzate & 5.69 & 0.2 & 7.1 \\
& & & \\
\hline
\end{tabular}


Effects of carbon and nitrogen sources. The MK production of strain $\mathrm{K}_{3}-15$ was compared with different carbon sources for cultivation times of at 24,36 and $48 \mathrm{hr}$, and the maximum amount in each culture is shown in Table I. Glycerol was the most effective carbon source for both growth and MK production. The high amount of MK in glycerol-grown cells was mainly due to the increased amount of MK-4. The amounts of MK-4 in cells grown on other carbon sources except for acetate were lower than those of MK-6.

Table II shows the effect of organic nitrogen sources on the MK production. Polypepton was the best nitrogen source for both growth and MK production. The high productivity of MK-4 was also observed only for the culture with Polypepton as the nitrogen source as in the case of glycerol as the carbon source.

The MK production varied with the concentrations of glycerol and Polypepton. Among the combinations tested, the amounts of MK-4 and MK-6 were high in cells grown on medium consisting of $2.5 \%(\mathrm{w} / \mathrm{v})$ glycerol and $2 \%$ Polypepton. The amount of MK-4 increased linearly in proportion to the glycerol concentration. Then, the effect of a high concentration of glycerol on the MK production was studied with medium containing $2 \%$ Polypepton (Fig. 3). Although the amount of MK-6 scarcely changed with increasing glycerol concentration, that of $\mathrm{MK}-4$ increased

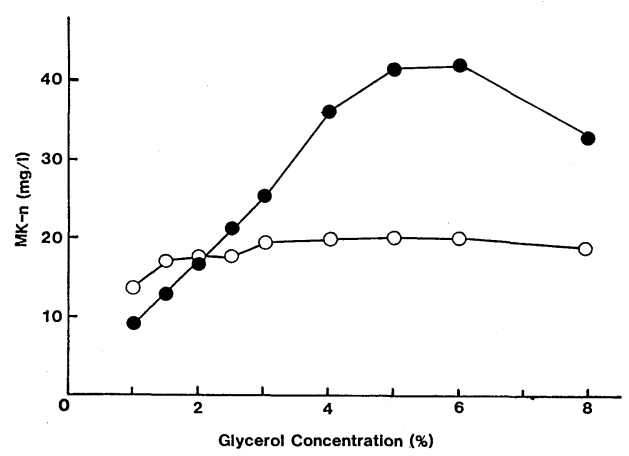

FIG. 3. Effect of the Glycerol Concentration on MK Production by Strain $\mathrm{K}_{3}-15$.

The strain was grown on the basal medium containing $2 \%$ Polypepton and different concentrations of glycerol. MK-4; O, MK-6. until $5 \%$ glycerol.

Further supplementation of inorganic nitrogen compounds and organic acids to the glycerol-Polypepton medium did not increase the MK production.

Effects of the concentrations of other components of the culture medium. The concentration of $\mathrm{K}_{2} \mathrm{HPO}_{4}$ strongly affected the MK MK production, the amount of MK being maximum at the concentration of $0.6 \%$. The production of MK-4 was much more sensitive to a change in $\mathrm{K}_{2} \mathrm{HPO}_{4}$ concentration than that of MK-6.

An increase in the yeast extract concentration did not influence growth, but the amounts of MK-4 and MK-6 produced increased up to the concentration of $0.3 \%$, and then abruptly decreased.

The effects of the concentrations of $\mathrm{NaCl}$ and $\mathrm{MgSO}_{4} \cdot 7 \mathrm{H}_{2} \mathrm{O}$ on the $\mathrm{MK}$ production were also investigated. On the addition of $0.4 \% \mathrm{NaCl}$ and $0.02 \% \mathrm{MgSO}_{4} \cdot 7 \mathrm{H}_{2} \mathrm{O}$, the amount of total $\mathrm{MK}$ reached $95.1 \mathrm{mg} / \mathrm{l}$ and $9.22 \mathrm{mg} / \mathrm{g}-\mathrm{DCW}$.

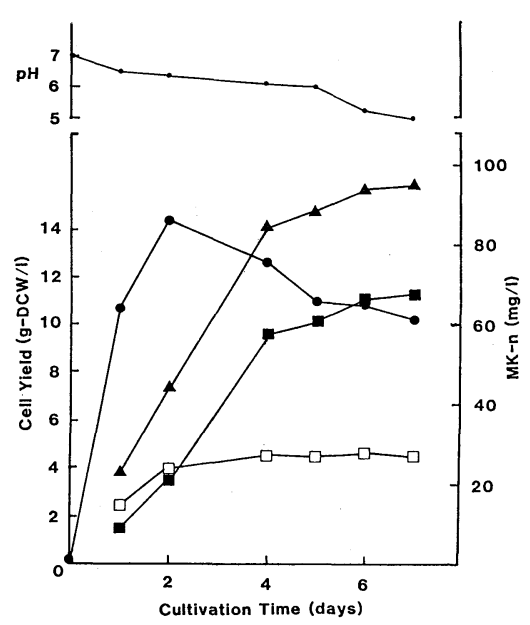

FIG. 4. Time Course of Production of MK-4 and MK-6 by Strain $\mathrm{K}_{3}-15$.

The modified basal medium containing 5\% glycerol, $2 \%$ Polypepton, $0.3 \%$ yeast extract, $0.6 \% \mathrm{~K}_{2} \mathrm{HPO}_{4}, 0.4 \%$ $\mathrm{NaCl}$ and $0.02 \% \mathrm{MgSO}_{4} \cdot 7 \mathrm{H}_{2} \mathrm{O}, \mathrm{pH} 7.0$, was used. The strain after preculturing in the basal medium for $24 \mathrm{hr}$ was transferred to $50 \mathrm{ml}$ of the modified basal medium in a $500-\mathrm{ml}$ shaking flask and then cultivated at $28^{\circ} \mathrm{C}$. yield; $\mathbf{\square}, \mathrm{MK}-4 ; \square, \mathrm{MK}-6 ; \boldsymbol{\Delta}, \mathrm{MK}-4+\mathrm{MK}-6$. 
Effects of temperature, $p H$ and aeration. When the cultural temperature was varied between 25 and $37^{\circ} \mathrm{C}$, the total amount of MK and cell yield were found to be maximum at $28^{\circ} \mathrm{C}$. The accumulation of MK-4 was more sensitive to a change in the cultural temperature than that of MK-6.

A relatively high amount of MK was obtained on cultivation with an initial $\mathrm{pH}$ of 7.0, and also of pH 6.0 and 6.5.

Strain $\mathrm{K}_{3}-15$ was cultured under different aeration conditions by changing the volume of the medium, between 25 and $150 \mathrm{ml}$, in a 500 $\mathrm{ml}$ shaking flask. The highest cell yield was obtained on cultivation in $25 \mathrm{ml}$ medium, but the production of MK-4 was very low. The highest productivity of MK-4 was observed when the cultivation was carried out with $50 \mathrm{ml}$ medium in the flask. On the other hand, the amount of MK-6 produced was almost the same under all aeration conditions.

Time course of $M K$ production under the optimal culture conditions. Figure 4 shows the time course of the MK production and growth of strain $\mathrm{K}_{3}-15$ under the optimal culture conditions established above. The cell concentration became maximum at 48 -hr cultivation and then decreased gradually. The amount of MK-6 in the culture broth increased with increasing cultivation time and almost became maximum, $30.0 \mathrm{mg} / \mathrm{l}$ and $3.0 \mathrm{mg} / \mathrm{g}-\mathrm{DCW}$, at $48 \mathrm{hr}$. However, the accumulation of MK-4 still increased in the stationary and death phases, becoming maximum, $68.6 \mathrm{mg} / \mathrm{l}$ and $6.87 \mathrm{mg} / \mathrm{g}-\mathrm{DCW}$, at 6 to 7 days.

Effects of various additives. Diphenylamine, linalool and tiglic acid, which were effective for the $\mathrm{CoQ}_{10}$ production by Pseudomonas spp., ${ }^{6)}$ and $\alpha$-pinene were added to the medium as ethanol solutions. $\alpha$-Pinene and diphenylamine increased the MK-4 production. When $\alpha$-pinene $(0.2 \mathrm{~g} / 1)$ was added, the total MK content reached $110 \mathrm{mg} / \mathrm{l}$ and $11.75 \mathrm{mg} / \mathrm{g}-\mathrm{DCW}$. The addition of diphenylamine $(5 \mathrm{mg} / \mathrm{l})$ increased the total MK content to $120 \mathrm{mg} / \mathrm{l}$ and $12.30 \mathrm{mg} / \mathrm{g}-\mathrm{DCW}$. Tiglic and linalool were more or less effective for the MK production.

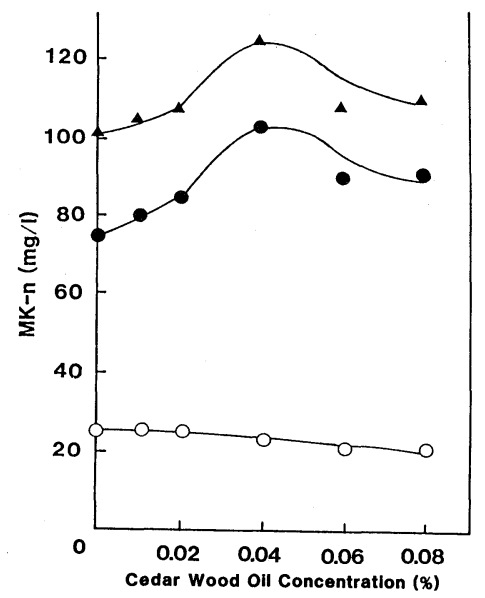

FIG. 5. Effect of Cedar Wood Oil on MK Production by Strain $\mathrm{K}_{3}-15$.

The strain was grown on the modified basal medium in Fig. 4 containing cedar wood oil., $\mathrm{MK}-4 ; \bigcirc, \mathrm{MK}-6 ; \boldsymbol{\Delta}$ MK-4 + MK-6.

A variety of natural oils were supplemented to the culture medium directly before autoclaving at the final concentration of $0.05 \%$. Among them, cedar wood oil decreased the growth but significantly increased the MK production. Figure 5 shows the effect of the concentration of cedar wood oil on the MK production. MK-4 production increased with increasing cedar wood oil concentration up to $0.04 \%$, whereas the amount of MK-6 decreased. The total amount of $\mathrm{MK}$ reached $125.4 \mathrm{mg} / \mathrm{l}$ and $12.80 \mathrm{mg} / \mathrm{g}-\mathrm{DCW}$.

The effects of prenyl alcohols such as isopentyl alcohol, dimethylallyl alcohol, geraniol and farnesol on the MK production, which stimulated the production of $\mathrm{MK}$ by F. meningosepticum ${ }^{2,3)}$ and that of $\mathrm{CoQ}$ by Pseudomonas schuylkilliensis, ${ }^{7)}$ and which possibly provided the polyprenyl side chain of MK, were investigated. N.one of the prenyl alcohols increased the MK production of strain $\mathrm{K}_{3}-15$ at concentrations of 0.5 and $1 \mathrm{mM}$, in fact, the amount of MK-4 decreased.

Among L-tryptophan, L-phenylalanine, Ltyrosine, anthranilate and phenylpyruvate, only phenyl pyruvate somewhat increased the MK-4 production in contrast with in the case 
of F. meningosepticum. ${ }^{3)}$

Precursors of the naphthoquinone nucleus and polyprenyl side chain of $\mathrm{MK}$, such as shikimate, $o$-succinylbenzoate, DHNA and mevalonate, were added to the culture medium. These compounds slightly stimulated the MK production at a low concentration, 0.01 or $0.1 \mathrm{~mm}$, but strongly inhibited it at a high concentration.

\section{DISCUSSION}

An MK-4 producer was obtained from Flavobacterium sp. 238-7, which contained MK-6 as the major component of the isoprenoid quinone system, as an HNA-resistant mutant. Such a change in the MK pattern was first observed with an HNA-resistant mutant of $F$. meningosepticum. ${ }^{2)}$ HNA was found to inhibit the MK biosynthesis ${ }^{3)}$ as a structural analog of DHNA, which is an intermediate of MK biosynthesis. ${ }^{8)}$ The MK-4 productivity was improved by further mutagenization leading to resistance to usnic acid and menadione. Usnic acid is an uncoupler isolated from Usnea barbata. Since Flavobacterium sp. 238-7 contains $\mathrm{MK}$ as the sole quinone, it is possible that the mutant might obtain the resistance throgh an increase in this component of the respiratory chain. Menadione is a synthetic naphthoquinone and exhibits vitamin $\mathrm{K}$ activity. But it inhibits mitochondrial phosphorylation by complexing with the functional sulfhydryl groups of enzymes. ${ }^{9)}$ The growth inhibition of Flavobacterium sp. 238-7 by menadione might be reversed with an increase in MK content on mutation.

The concentration of oxygen in the culture medium might be an important factor for MK production because $\mathrm{MK}$ is a component of the electron transport chain. ${ }^{2,10}$ ) The MK-4 production required a relatively high oxygen supply but an excess supply led to reduced production. This was different from in the case of MK-6 production by $F$. meningosepticum. ${ }^{3)}$

The improvement of $\mathrm{MK}$ production on mutagenization and optimization of the cultural conditions is shown in Fig. 6. The MK

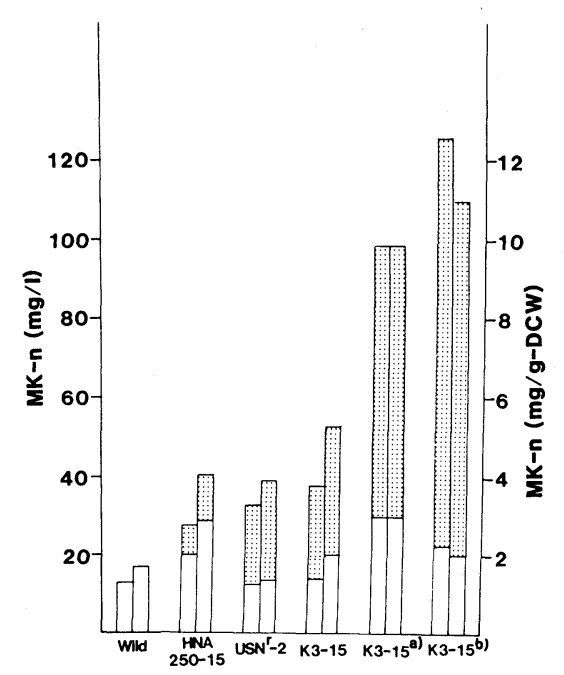

FIG. 6. Improvement of MK Production by Flavobacterium sp. 238-7.

The left and right bars indicate the amount of $\mathrm{MK}$ in $\mathrm{mg} / \mathrm{l}$ and $\mathrm{mg} / \mathrm{g}-\mathrm{DCW}$, respectively, the open and shaded bars denoting MK-6 and MK-4, respectively. The amounts of MK produced by each strain indicated are the values when grown on the basal medium, except that $\mathrm{K}_{3}-15^{\text {a) }}$ was grown in the modified basal medium in Fig. 4 and $\mathrm{K}_{3}-15^{\text {b) }}$ in the modified basal medium supplemented with cedar wood oil.

productivity of strain $\mathrm{K}_{3}-15$ was almost ten times that of the wild type strain. It is noteworthy that the increase MK was due to an increase in MK-4 but not MK-6. MK-4 was a minor component of the wild type strain. The physiological role of $\mathrm{MK}-4$ in the mutant strain is uncertain. In the course of cultivation, the cellular content of MK-4 still increased after the growth had reached the stationary phase. This is similar to in the case of the accumulation of secondary metabolites such as antibiotics.

\section{REFERENCES}

1) Y. Tani, S. Asahi and H. Yamada, J. Nutr. Sci. Vitaminol., 32, 137 (1986).

2) Y: Tani, S. Asahi and H. Yamada, Agric. Biol. Chem., 49, 111 (1985).

3) Y. Tani, S. Asahi and H. Yamada, J. Ferment. Technol., 62, 321 (1984).

4) Y. Tani, T. Nakamatsu, Y. Izumi and K. Ogata, Agric. Biol. Chem., 36, 189 (1972).

5) H. Mayer and O. Isler, "The Vitamins," Vol. III, ed. 
by W. H. Sebrell, Jr. and R. S. Harris, Academic Press Inc., New York, 1971, p. 418.

6) K. Aida, K. Uchida and I. Kawada, Jap. Pat., 21756 (1980); N. Shirota, T. Sakata, T. Morinaga and J. Ohta, Japan Patent, 154994 (1981); K. Yokozeki, H. Hirashima and S. Yamanaka, Japan Patent, 129695 (1982).

7) I. Kawada, K. Uchida and K. Aida, Agric. Biol.
Chem., 44, 465 (1980).

8) R. Bentley and R. Meganathan, Microbiol. Rev., 46, 241 (1982).

9) R. D. Dallam and J. W. Hamilton, Arch. Biochem. Biophys., 105, 630 (1964).

10) W. J. Polglase, W. T. Punn and J. Withaar, Biochim. Biophys. Acta, 118, 425 (1966). 